\title{
CAAD AND ITS INFLUENCES ON ARCHITECTURAL STUDENTS (CREATIVITY IN GLOBALIZATION ERA)
}

\author{
Haitham Sadek Abdullah Selim \\ Department of Architecture, Faculty of Engineering, Al-Azhar University, Cairo, Egypt \\ E-mail: haitham.selim@gmail.com
}

\begin{abstract}
Intense technology usage in education has been increasing in every field recently, because computer based visual technology has been improving and becoming the most communal trend in the recent years. In addition to these decreasing prices of the computer-based systems make this trend more attractive and usable. Indeed the Architectural education is one of the most difficult and expensive kind of education which based-on visual material, that's why computers and complicated software usage in architectural education has increased dramatically. Nowadays, there is no there is no doubt it is not possible for an architectural company or educational organization to compete, in the globalization era, without taking the advantage of computer software. As a result of debating on the use of CAAD in architectural schools, this paper aims to examine the objectives of existing literature together with the response and observation of students give a remedial on the use of CAAD if it should be encouraged or discontinued ,furthermore, study quantitatively explores students' preferences and attitudes toward the use of CAAD (Computer - Aided Architectural Design) tools, then assesses the potential impact of these digital tools on the quality and creativity of architectural design final product, trying to investigating in what motivates the student to use CAAD software in the design process? What is the importance of the role of CAAD in an architectural curriculum? And the impacts do CAAD tools have on the overall quality of architectural design in all of its stages (conceptual, design development, presentation).
\end{abstract}

Keyword: CADD- design process- creativity- CAE- globalization

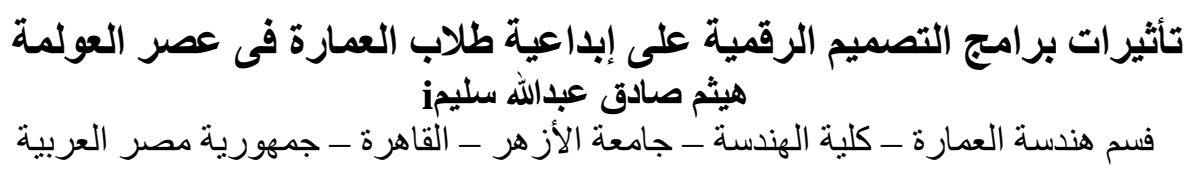

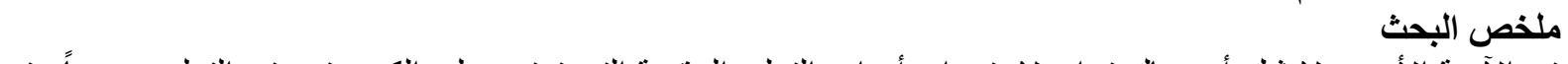

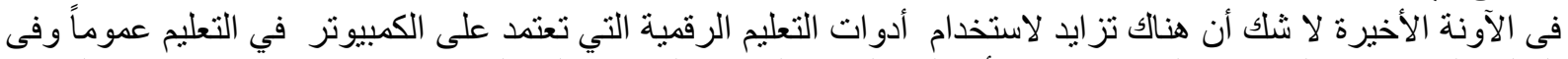

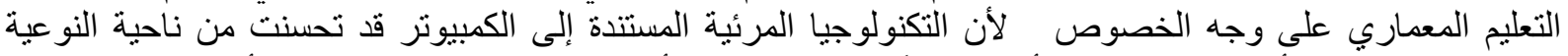

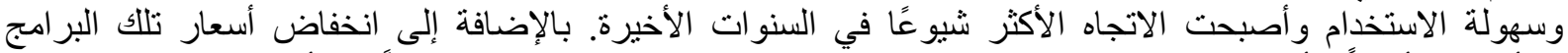

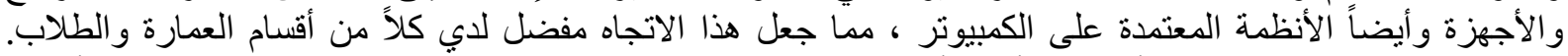

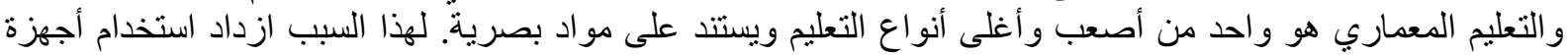

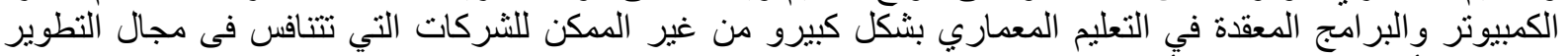

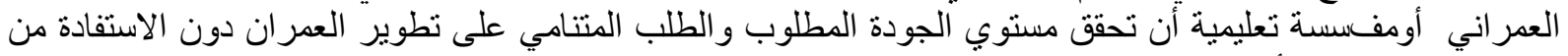

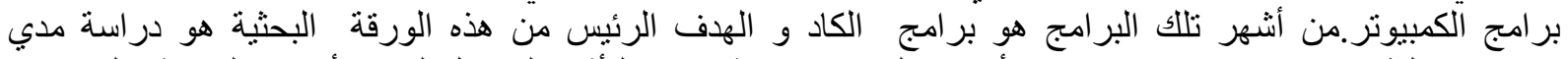

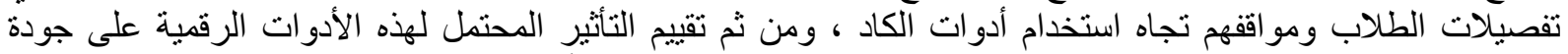

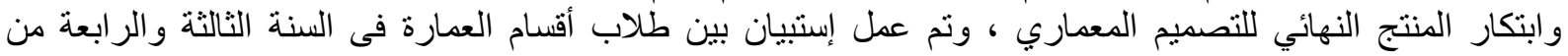

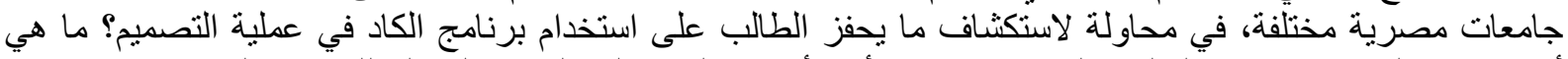

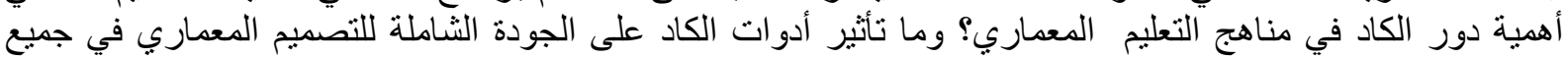




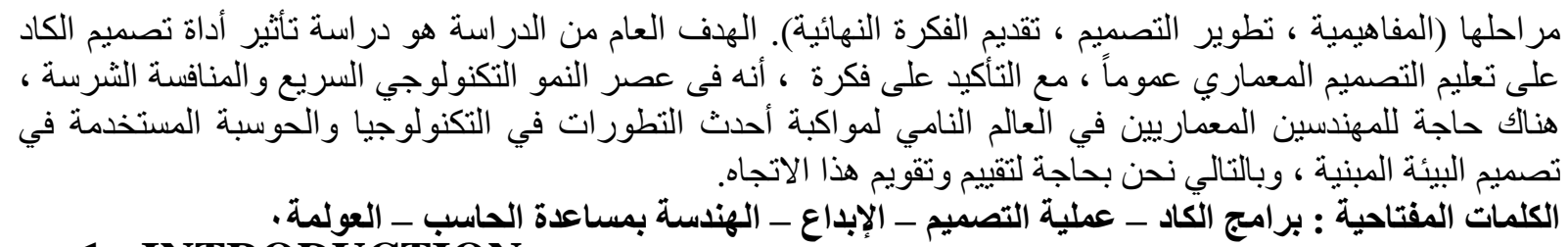

\section{INTRODUCTION}

There is no doubt, with the arrival of Information Technology era a few decades ago, there has been massive improvement in various professional fields given new software development tools, programming languages and methodologies. Today, the work of architectural students has become a lot easier when compared to decades ago as a result of development of personal computers and software (MÂRŞANU, Rusu, \& Management, 2010).

Computer Aided Design (CAAD) frugally refers to the process whereby computers and specialist software are used to produce virtual three-dimensional models and two dimensional drawings of products(AP \& Science, 2015). There are several types of

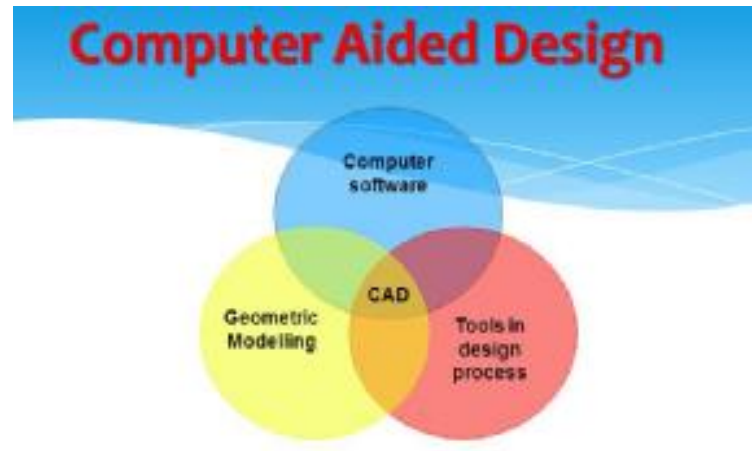

The integration of computer software and geometric model to serve the design process

Figure 02 integration of computer and design process. https://slideplayer.comSource :(

CAAD software which have been developed for use over a range of applications and industries. CAAD was approved into most of architectural departments in the Egyptian universities, nevertheless students are not allowed to use it except if they finish their first two years of the architectural education program as they must, due to their curriculums, to learn the freehand sketching and other hand communication skills in order to apply it in their designs.

Notwithstanding, from the third to the final years they are encouraged to merge both methods in design and drafting, that are the traditional and the CAAD, this transition is not clearly addressed; thus, students are left unable to implement this blend of methods when needed. furthermore, many students are not able to utilize CAAD tools in design different processes, for instance, they cannot apply CAAD to preferable awareness their projects' different components, systems and need. CAAD tools and software are not taught as design or analyzing tools or programs, thus students are not able to analyses the environmental aspects of the site, It is taught only as a drafting tool as an alternative to traditional methods. As a consequence, students are not able to implement their learned skills in CAAD to their design projects in practical manner to deliver integrated designs.

\section{HYPOTHESIS}

Nowadays, we are in era of rapid technological growth and fierce competition, there is the need for architects to keep pace with the latest advancements of technology and computing used in the design of the built environment. According to Yehuda, the current concept of architectural design education is a blend of the traditional method of drafting on paper and the modern method of using CAAD in the design process. This paper argues that the transition to the new digital media has been vague and largely ill-defined, which causes several serious pedagogical problems. The introduction of these new tools into design teaching has been combined with a dysfunctional relationship between the tools and the intended end tasks (AlMatarneh \& Fethi, 2017). Consequently, this dysfunction has resulted in a separation between architectural design and the context of the project, specifically its sense of scale and proportion, and has led to a marked decline in the spatial quality experience and a disproportionate dependence on illustrative techniques. The inappropriate use of the digital tools and the heavy reliance on them, the lack of integration among different digital tools and, more importantly, the absence of effective coordination between theoretical courses and design projects has resulted in a relatively poorer overall architectural design product. The 
main concern is "do computers aid the design process after all?" as asked by Brown who saw the relationship between the interface and its user as not one-sided. He stated that many have unjustly believed that technology stormed and forced its way into our lives and society, rather society has welcomed it and allowed it grow for a reason(Brown \& Society, 2009). Furthermore, CAAD is taught in isolation of other design courses in the department. This does not only limit the creativity of students but it does not motivate the students to learn the tool. In architectural education passive learning do not help students as it largely a one-way process where there is not much interaction between the students and the teacher besides it ignores individual differences which is not welcome particularly in architectural design education. The main concern is "do computers aid the design process after all?" as asked by Brown who saw the relationship between the interface and its user as not one-sided. He stated that many have unjustly believed that technology stormed and forced its way into our lives and society, rather society has welcomed it and allowed it grow for a reason(Brown \& Society, 2009).

\section{METHODOLOGY}

Methodology of this paper is based on two main pillars; literature review and questionnaire, the use of quantitative method was employed to obtain data. This quantitative method classified the population into three groups of students from local university (Al-Azhar /AinShams-/Future university) undergraduate students from third and final year. Questionnaires

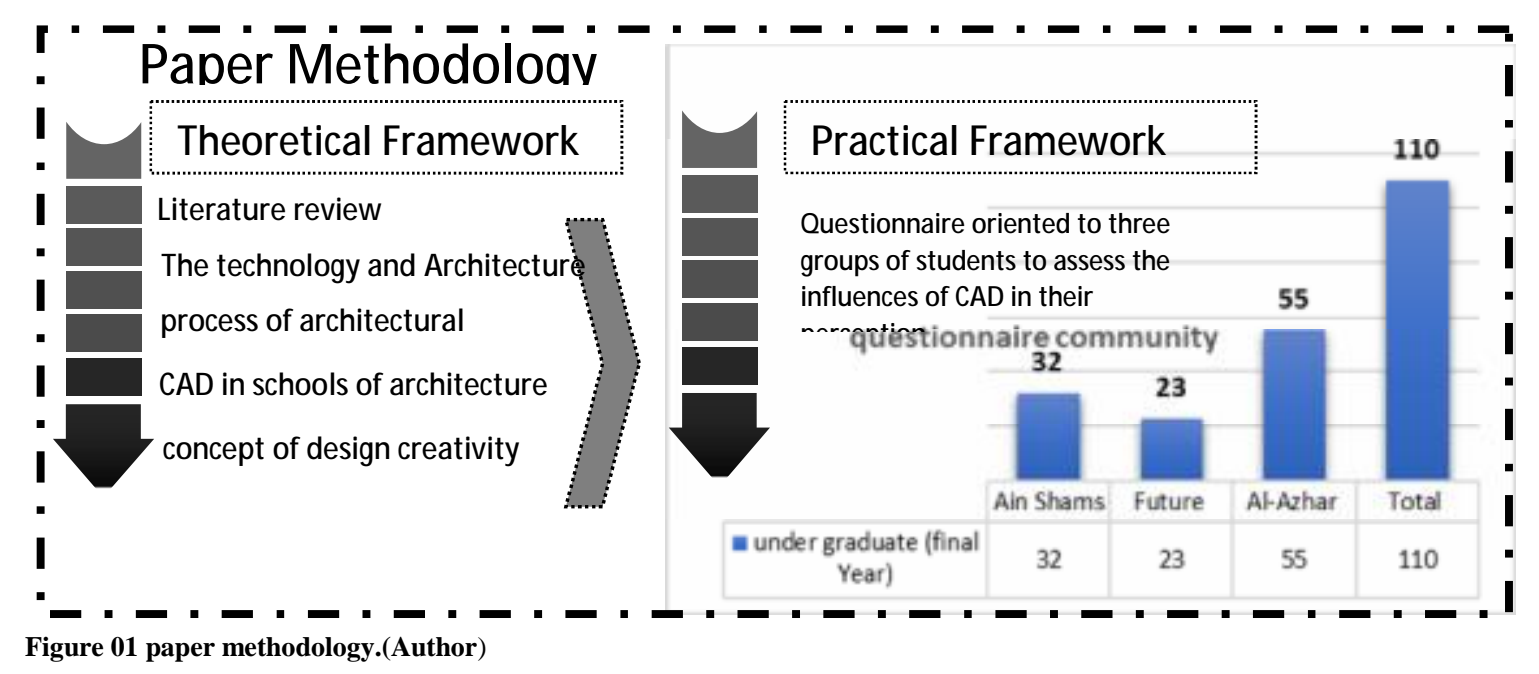

were used to obtain data from the groups.

\section{Theoretical Framework \\ The technology and Architecture (Historical Review)}

Architecture is a technology-intensive discipline. It uses technology-both in the process of designing and in its products - to achieve certain functional, cultural, social, economic, and other goals. The importance of technology to the discipline and to the practice of architecture, and through them to society as a whole, has been demonstrated again and again in history: the adaptation of the Etruscan keystone arch enabled Roman engineers to build extremely strong and

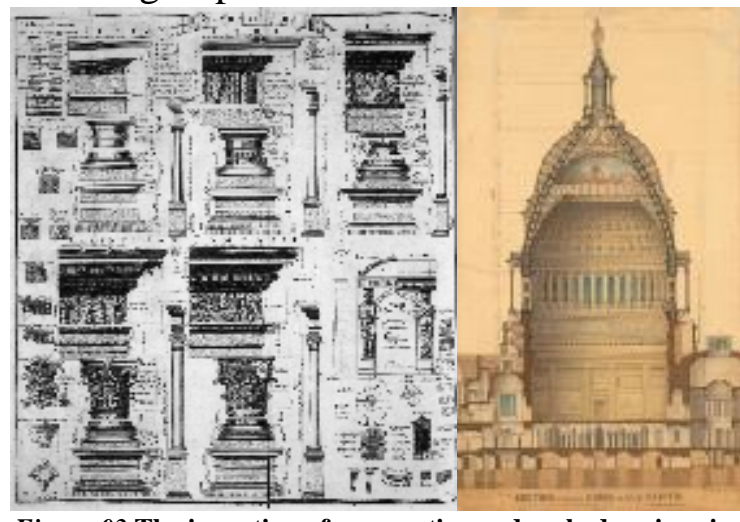

Figure 03 The invention of perspective and scale drawings in the 15th century radically transformed the practice and products of architecture. Source : (Selim 2015) durable bridges, and led them to invent the dome as early as 27 BC. The invention of the Flying Buttress allowed 12th century Master Builders to replace the Romanesque's massive walls by the relatively thin and tall walls and soaring 
vaulted ceilings of the Gothic Cathedral. The invention of perspective and scale drawings in the 15th century radically transformed the practice and products of architecture, and created the office of the Architect, as distinct from the Master Builder. Henry Bessemer's invention of mass-produced steel in 1855(Birat \& Steelmaking, 2004), coupled with Elisha Otis' invention of the safety elevator in 1853, and Werner von Siemens invention of the electric elevator in 1880, allowed architects such as Daniel Burnham to design and build skyscrapers as early as 1902 (Goetzeler, 1994). The advent of the automobile at the beginning of the 20th century is a case in point: it was intended to be a means of transportation, not much different than the horse and carriage that preceded it (indeed, it was called a "horseless carriage"). Its inventors and users have never imagined that this purely technological devise will lead to the creation of suburbs, freeways, shopping malls, drive-throughs to global dependence on oil along with its political consequences, global warming, and more.

In the same fashion, the transformation of the computer itself provides further proof to this socioecological phenomenon: when general purpose computers were first introduced after world war II. During World War II, advances in military technology had created a need for individuals called "computers" who could solve the lengthy and complicated equations needed to aim and target large ballistic weapons. As with most wartime positions, there were few qualified men who were available for the job. So, in the 1940s, the U.S. Army recruited over 100 women to work as computers at the Army's Ballistic Research Labs in Philadelphia, Pennsylvania. Computers in the early stage, was cost millions of dollars, filled entire rooms, and were used for such tasks as accounting and statistical calculations. they were evidences of governmental power, there was nothing "personal" about then. Eventually six decades later, after the first introduction of computers into

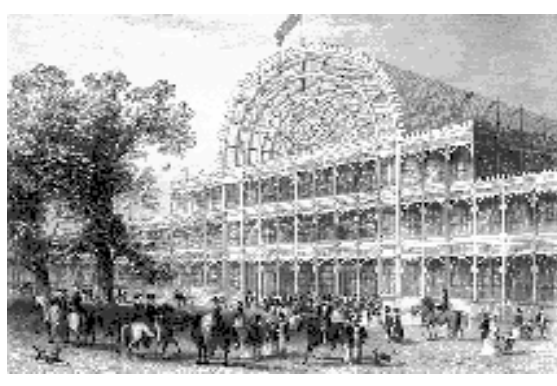

The Crystal Palace, 1851, was one of the first buildings to have cast plate glass windows supported by a cast-iron frame . Source

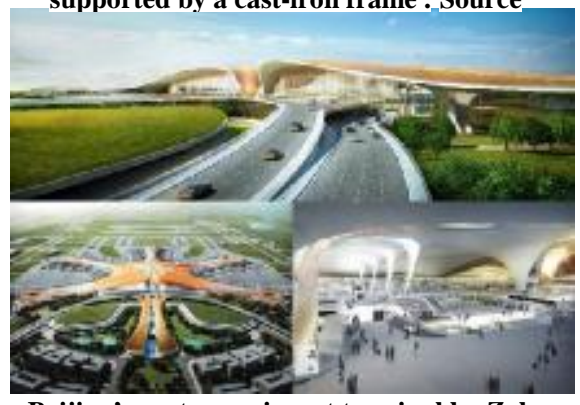

Beijing's vast new airport terminal by Zaha Hadid 2019.Source(www.designboom.com) Figure 04 the technological revolution and its relation with architectural products

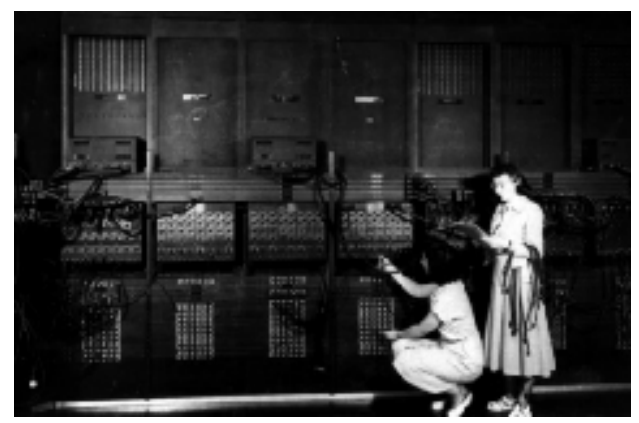

Figure 05 beginning of computer manufacturing the Electrical Numerical Integrator and Computer completed in 1945.source (www.dreamhost.com) architecture, their effects on the discipline, the practice, and the products of architecture are becoming evident. with the help of many technological improvements, the computer came to be seen as empowering people, rather than suppressing them. And their use has proliferated to every aspect of our lives, changing our lives immeasurably from what they were in 1960s. as educators and researchers, we must assess premises and purposes of the new technologies so that we may assess what has been displaced and adapted, what has been gained, what is new, and predict and direct the future of our discipline along with the affordances of the new technologies. it is not enough to assume that our new design technologies help architects to work more intelligently, more responsibly, more effectively, and more collaboratively. Thus, technological innovations - often several of them coming together at the same timehave always had a significant impact on the discipline and practice of architecture. In the $21 \mathrm{st}$ century, the advent of computer-aided design, computer-assisted collaboration, computerassisted construction technologies, computer-controlled buildings, and Internet based 
"virtual" places, this is refer to have as much of an impact on architectural design processes and products as these earlier technological advances have done.

\section{The process of architectural design}

Architectural design is one kind of problem solving which primarily involves a series of actions that must be performed in order to solve a design problem (Chan, 1990). According to Lawson, Architecture is the art and technique of designing the "enclosure" of space for human use, as distinguished from skills associated with construction. As with some other arts, the development and practice of architecture embraces both aesthetic and utilitarian ends; these ends may be distinguished from each other but not separated completely, furthermore, the relative weight given to each end, purpose, or motif, may vary widely from one architectural project or work of art to another. Although creativity and creative thought can be applied just as much in science, philosophy, the law, management and many other fields of human endeavor.(Lawson, 2006 )

Designing is an "activity which incorporates both physical and conceptual tools in an architectural design process, besides the physical tools such as all the drawing and drafting

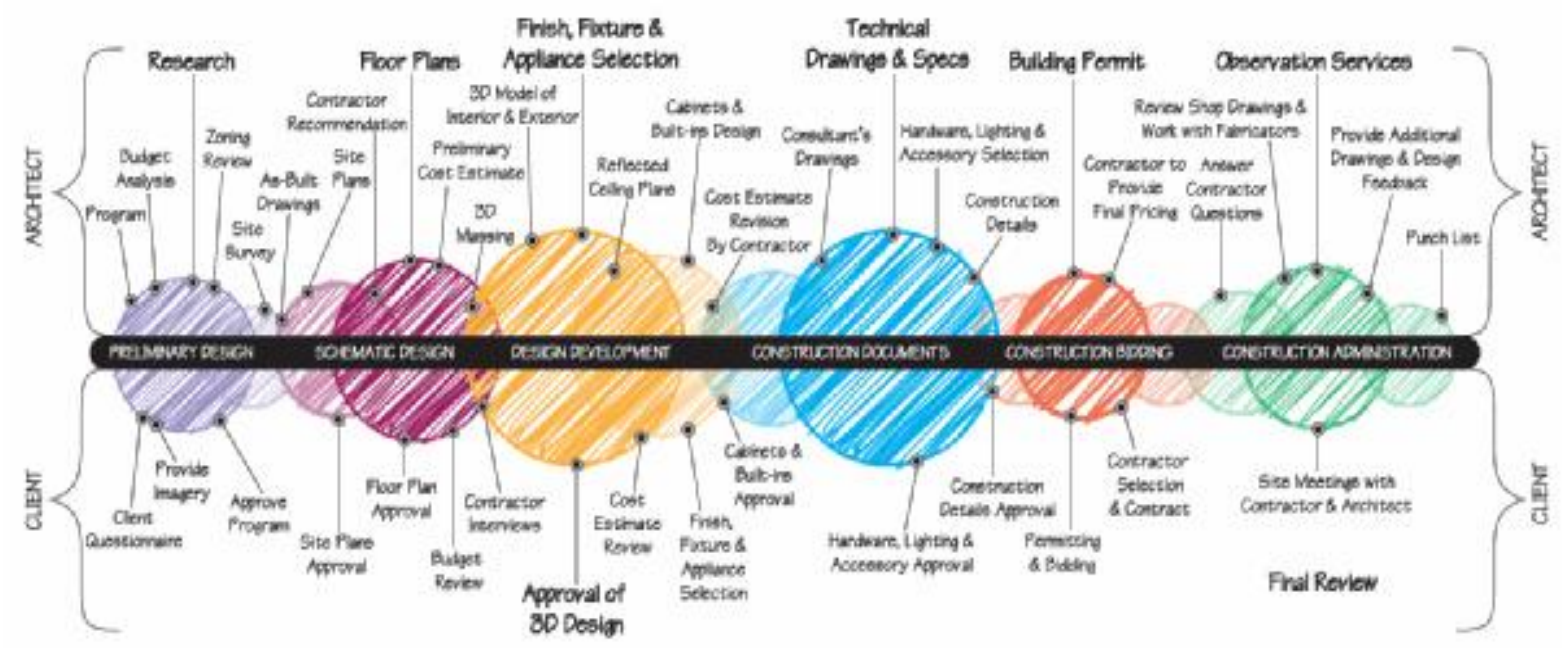

Figure.06 process of architectural design from idea to accomplish (https://pistonclasico.com/wall/architectural- process2019)

instruments, several conceptual tools such as the shape grammar and library are used. These conceptual tools are the ones that designers use to abstract and comprehend the design problem, mentally reconstruct, figure out and resolve it thus generate the design idea and the physical tools are the ones to visualize and realize the design (Hatem, 2005). The design process is a creative problem solving endeavor that transforms ideas and visions into the three dimensional reality of the architectural product, the concept of abstraction (or modelling) in architectural design is historically linked to the level of complexity of the design product. It involves the representation of existing structures and can be described as an attempt to recreate reality. The process of architectural design since its first inception has aimed at the production of 'good' buildings. The process itself, the teaching of design, and the evaluation methods and criteria, are subject to change and depend on the state-of-the-art in research and technology. Developments in the field of computer modelling, computer graphics and more recently in cognitive psychology and artificial intelligence provide the theoretical basis to build fundamentally new tools to support the architectural design process, in particular for design abstraction and evaluation.(Guney \& Sciences, 2015). Therefore, we can consider the design process like involves the representation of existing structures and can be described as an attempt to recreate reality. Eventually, developments in the field of computer modelling, computer graphics and more recently in cognitive psychology and artificial intelligence provide the theoretical basis to build fundamentally new tools to support the architectural design process, in particular for design abstraction and evaluation (Szalapaj, 2013).From the author point of view students should be taught that the design process does not end with the 
initial ideas, but extends to study how to implement this idea and use the techniques of the computer software not only to produce forms that cannot be applicable.

\section{The concept of design creativity}

Creativity is defined as giving birth to ideas, concepts and values that have never been thought of before, also, creativity is finding new methods that would enhance and develop the human intelligence and creativity did not simplify the problem but raised its complexities. Although creativity is a simple phenomenon, it is in fact quite complex in itself.

creativity concept has been studied from the perspective of artificial intelligence, design research, behavioral and social psychology and cognitive science and many others(Kane, 2005).

It's the process which consists largely of re-arranging what we know in order to find out what we do not know (Musa,2013). According to E G Wilson, he explains creativity like "the love of complexities without reductionism".

Creativity can simply be seen as the development of ideas or work that is usually useful and original(Amabile, Conti, Coon, Lazenby, \& Herron, 1996). Four major elements were given by Robinson for creativity and these are; the medium, expertise in or mastery of the medium, the need to play and take risks and the need for critical judgement(Robinson, 2011).According to Runco creativity plays a significant role in the process of cultural reproduction, technological advancement, innovation and intervention(Kozbelt, Beghetto, \& Runco, 2010).

Barrow argued that, creativity is an innovative way of thinking and is the basis for any successful architect as it provides the essentials for producing new ideas and values in sciences. Not until recently and by the emergence of information technology has the gap between arts and sciences (both include architecture) been widely narrowed? In the fifties and sixties most artists were nervous when it came to scientific analysis as they felt that it destroyed parts of the human aspect and creativity (Barrow 2003).

In the same fashion, creativity can be seen as a key element of design which is a very important for innovation and change (Williams, Ostwald, \& Askland, 2010) Barrett and Donnelly give an enlightening four-dimensional philosophical view on creativity which is: "firstly, something everyone has - an anthropological capacity; second, something one ought to have - a binding norm; third, something one can never have enough of a telos without closure; fourth, something that can be intensified through methodological instruction and exercise - a learnable competence." (Barrett, Donnelly, \& teaching, 2008).

Design entails the imagination and development of new realities meaning central to a designer's work is the quest for a cutting edge and unusual solutions to problems which is in contrast other sciences which focus on the analysis and description of existing realities. Also in contrast to the arts, design is basically directed by human purposes towards the actualization of the intended functions, thus emphasizing the significance of meeting requirements and generating proper solutions (Alexiou, Zamenopoulos, Johnson, \& Gilbert, 2009). According to Jefferis \& Madsen , architectural designers continue to make sketches while the computer waits for input, computer can assist in the design process but individual creativity takes place even before the computer is turned on(Jefferis \& Madsen, 2005).

Creative thinking is associated with how people handle problems and is dependent on an individual's personality and thinking/working style. Motivation is usually as important for creative production and the main motivators are inborn passion and interest in the work itself(Lawson, 1979).

Indeed, CAAD has enhanced creativity and there is a more effective management of the repetitive areas of design. An example is seen in the design of apartment complex or a block of flats whereby an initial unit is designed and then a number of the same units are attached together as desired in a swift manner. Some units can be increased or reduced in size, or a quick implementation of alternatives for bedrooms and baths.

On the side, many of architecture instructors said: CAAD decreasing design and imagination ability of students, and cause negative impact on contemporary design creativity, low quality design technology addiction, less personal contact and interaction between students and advisors, instead of better design, better visual outputs are preferred and inadequate literature follow. In relation to architecture, Sidawi reviewed some literature by many writers and 
found out from a creativity perspective as seen in many cases that students were able to develop new architectural solutions but not creative ones (Sidawi, 2013). According to Guney the cons of using CAAD tools is to make the students addicted and design their projects without creativity (Guney \& Sciences, 2015).

yet, many educators and practitioners have called for a combination of both physical and digital design methods rather than the use of either method separately. Breen indicated that the combination of both techniques gives the designer added insights and more "real" approaches to develop, reconsider and refine any design. Breen also emphasized that the combination of both techniques should be actively incorporated in the educational curriculum to prepare the students as they move toward practice(Al-Qawasmi, 2004).

\section{Computer in architecture (pros and cons)}

Indeed Computing in architecture has posed new challenges since its early beginning; it has changed the working methods in the architectural profession and study(Benton, 2007). The introduction of computer technology has provided architects with new affordances and has begun to displace previous design technologies. It is obvious that the efficiency, control, and intelligence made possible by computational tools are increasingly essential to architectural practices.

trials of using computer in architecture start very early with a very well known Egyptian

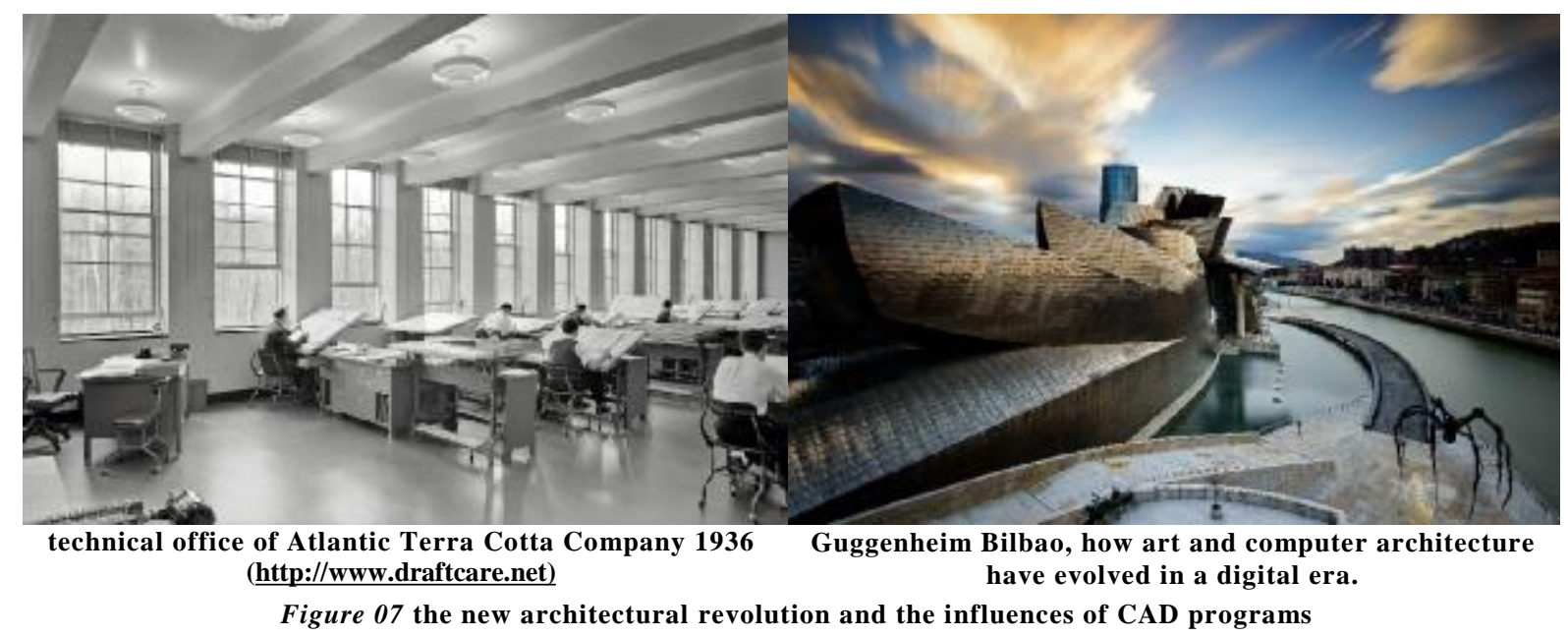

professor M.Z.Eldras (Moore, 1974), The use of Computer aided architectural design (CAAD) tools by architects' dates back to the early 1960s. CAAD tools are used by architectural firms and they greatly help in the production of drawings from inception to completion (Asut, 2008) it has reduced the need for draftsmen in offices thus reducing the number of human labor, resulting in an increase in productivity. However majority of architects in the developing countries may not be fully aware of the applications of computers in architecture except for the applications of computer aided drafting, modeling and visualization(Kyratsis, Bilalis, \& Antoniadis, 2011).It is almost half a century since computers have been used in building design. Their first use was in structural analysis and construction planning. The use of computers in building design analysis has included extensive developments in the analysis of building structure, HVAC (heat, ventilation and air condition) and environmental performance of buildings. Recently, sophisticated analyses of environmental behavior and the behavior of building users have been developed and implemented. Computer graphics was developed initially in the 1960s and formed the basis of computer-aided drafting systems, termed as CAAD systems. These systems are used during the development and documentation phases of building design. CAAD systems have been developed beyond simply drafting to modelling the geometry of the building. Today's commercial CAAD systems are used at various stages in the building design process and are integrated with analysis tools (Gero, 2002). Students are restricted from using CAAD tools in the first and second years of their architecture training. They are taught the basic hand drafting and graphic communications skills and other forms of conventional architectural design education. They are expected to apply such skills into their designs. However, in the 
third to sixth years of their architectural education, they are encouraged to use both traditional methods and computer aided drafting and design methods. Sadly, the transition from tradition methods to computer aided drafting design methods are not clearly defined, thus some students are left at a disadvantage when tasked to use CAAD in their design thus deprived of the tremendous advantages of using CAAD. On the other hand, A major advantage of this method is that, students are introduced to both methods of architecture design education and are able to implement either or both methods when needed. CAAD is the solution. CAAD offers the means of evolving design ideas in a three Dimension (3D) space that addresses all design issues that would have otherwise been ignored in two Dimension (2D) drawings on the sheet. CAAD tools enable the architect to better understand the various components of the project, its structural integrity, Heating, Ventilation and Air Conditioning, analyzing the environmental performance of the building and performing real life simulations in virtual reality systems.

The first-generation design tools that have emerged from the early computer technology development have mainly concentrated on model building for drawing production, with the exception of few design evaluation systems. Nowadays, Computing technology has achieved in the last two Decades a tremendous advance; for example, processing speed and circuit density have increased by order of magnitude. The software field has also progressed considerably, with new software development tools, programming languages and methodologies.(Ceccato, Hesselgren, Pauly, Pottmann, \& Wallner, 2016).

The major CAAD software for architecture includes; Auto CAAD by Autodesk, Revit Architecture also by Autodesk, Data CAAD by DATACAAD LLC, Free CAAD by Juergen Riegel, Chief Architect Software and ArchiCAAD by Graph iSOFT (AP \& Science, 2015). SketchUp by Trimble is also a CAAD software. Mârşanu and Rusu noted that the architect or student isn't just concerned with the look of a building and how it fits into the environment, but also with the bearing capacity of walls, the existence of efficient systems to ensure heating, ventilation, supply electricity and water (MÂRŞANU, Rusu, \& Management, 2010).

Walther, Robertson and Radcliffe in looking at the educational context on the use of CAAD noticed the student's inability to use suitable forms of communication such as sketches or verbal explanations to convey his design ideas, this was as a result of a combination of the enhanced visualization capabilities of CAAD and the significance that design education puts on the value of CAAD models. The assessment of student work showed this, they recommended that educators should avoid confined thinking and promote good design in their students by making sure the students become aware of the realities of continual and repetitive design, rather than controlled in their thinking by the capabilities of CAAD (Walther, Robertson, Radcliffe, \& Software Engineering, 2007) . During the current period, continuous research and development in the computer aided design field, has enabled to harness this computer power, and provide designers with new tools, hence, computer-based design tools offer significant advantages over traditional design practice. In fact, they allow performing design operations in ways that have never been possible in the past (Oxman, 2006)

Unfortunately, Botchway, Abanyie and Afram stated that students of architecture middle east did not enjoy the full benefits of using CAAD tools in the design process as a result of several problems like: lack of adequate logistics for teaching and practicing CAAD, the absence of CAAD training experts, complexities in the user interface of CAAD tools and the weak creativity of the development work in CAAD (Botchway, Amos-Abanyie, \& Afram, 2015).

Negroponte cautioned designers to be weary of the computer because it could affect their creative thinking, he suggested that designers should consciously distinguish between "heuristic of form" and heuristic of method". According to Negroponte, this would create a symbiotic relationship between the architect and the tool. (El Shafie, 2000)

\section{Objectives of computer aided education (CAE)}

Computer-aided engineering (CAE) is the broad usage of computer software to aid in engineering analysis tasks. It includes finite element analysis (FEA), computational fluid dynamics (CFD), multibody dynamics (MBD), durability and optimization.(Saracoglu \& Gozlu, 2006) The use of computer networks and information technology are becoming an important part of the everyday work on almost any profession, especially in the scientific areas and changed education concepts and many universities and education organizations decided to plan new strategies concerning computer-based technologies. As a result of these developments Computer Aided Education (CAE) methods came out. These methods have 
been utilized and developed more than for fifteen years in many universities and organizations. The aim of CAE is to develop the learning capacity of students and increase the teaching productivity and effectiveness of instructors with the help of advanced computerbased technology. This technology should be an integrated part in the education. It is also desirable to use this technology to develop attractive courses for distance education. Another area of interest is to use computers, information technology and equipment to develop attractive and understandable demonstrations of basically tasks and typical projects in the field of architectural education. (Femenías, 2004) Using CAE methods students can state and explain the basic concepts in the subject easily and are able to participate in discussions of advanced concepts related to the subject content. With the visualization techniques computer graphics images are created and these images display the data and the mathematical relations of the interested subject for the interpretation, particularly of multidimensional cases. CAE provides also the substructure for interactively communication possibilities with international colleagues and presentation of the subject interested worldwide. (Angelo \& Cross, 2012)

\section{Questionnaire Design}

After the above discussion, paper has been investigating the CAAD influences in the architectural student's society in Egypt in order to assess their awareness about CAAD. Through personal interviews and emails with students from three different architectural departments in Egypt, 160 copies of the questionnaire were distributed to participants among which only 110 questionnaires were completed in a 3-month period. The themes covered are CAAD influences in architecture, drafting tools, A number of difficulties and reservations were faced throughout this process. For instance, some questions were not fully responded to, some had answers not apparently relevant to the questions, while others were answered with a seemingly lacking interest in the themes of the questionnaire. Consequently, this study does not take into consideration inappropriate or irrelevant answers. Furthermore, some participants expressed their reservations towards the length of some of the questions. A number of participants also preferred not to be named. The questionnaire included a set of nine main and clear questions to measure the influences of CAAD programs on students of architecture, the questionnaire was completed through interviews with students at the college's computer labs and design studios.

\begin{tabular}{|c|c|c|c|c|c|}
\hline 1 & $\begin{array}{l}\text { how long you have been using } \\
\text { CAAD. }\end{array}$ & 1-3 years & 3-5 years & $5-8$ years & $\begin{array}{l}\text { over } 8 \\
\text { years }\end{array}$ \\
\hline 2 & $\begin{array}{l}\text { do you think CAAD enhancing } \\
\text { creativity }\end{array}$ & strongly agree & equivocal & conflict & $\begin{array}{r}\text { robustly } \\
\text { conflict }\end{array}$ \\
\hline 3 & $\begin{array}{l}\text { do you think manual drawings } \\
\text { being better than the use of } \\
\text { CAAD? }\end{array}$ & strongly agree & equivocal & conflict & $\begin{array}{r}\text { robustly } \\
\text { conflict }\end{array}$ \\
\hline 4 & $\begin{array}{l}\text { using of CAAD outputs to present } \\
\text { primary ideas to their colleagues } \\
\text { and lecturers. }\end{array}$ & overwhelmingly & often & on occasion & scarcely \\
\hline 5 & $\begin{array}{l}\text { do you think CAAD enhancing the } \\
\text { drawings quality }\end{array}$ & strongly agree & equivocal & conflict & $\begin{array}{r}\text { robustly } \\
\text { conflict }\end{array}$ \\
\hline 6 & $\begin{array}{l}\text { using of free hand to present } \\
\text { primary ideas to their colleagues } \\
\text { and lecturers. }\end{array}$ & overwhelmingly & often & on occasion & scarcely \\
\hline 7 & $\begin{array}{l}\text { using of verbal communication to } \\
\text { present primary ideas to } \\
\text { colleagues and lecturers and. }\end{array}$ & overwhelmingly & often & on occasion & scarcely \\
\hline 8 & $\begin{array}{l}\text { usage of the traditional board or } \\
\text { manual tools to present primary } \\
\text { ideas colleagues and lecturers. }\end{array}$ & Overwh- elmingly & often & on occasion & scarcely \\
\hline 9 & $\begin{array}{l}\text { do you think CAAD enhancing the } \\
\text { imitating of ideas and projects }\end{array}$ & strongly agree & equivocal & conflict & $\begin{array}{l}\text { robustly } \\
\text { conflict }\end{array}$ \\
\hline
\end{tabular}

Figure 08 questionnaire design (author) 


\section{Questionnaire Results}

nearly half of the sample have been using CAAD for about 1-3 years and 30 percent about 35 years with only a few using CAAD for more than 8 years as shown in illustration 1 .

whereby most students started using CAAD at the third-year level while a few before the final

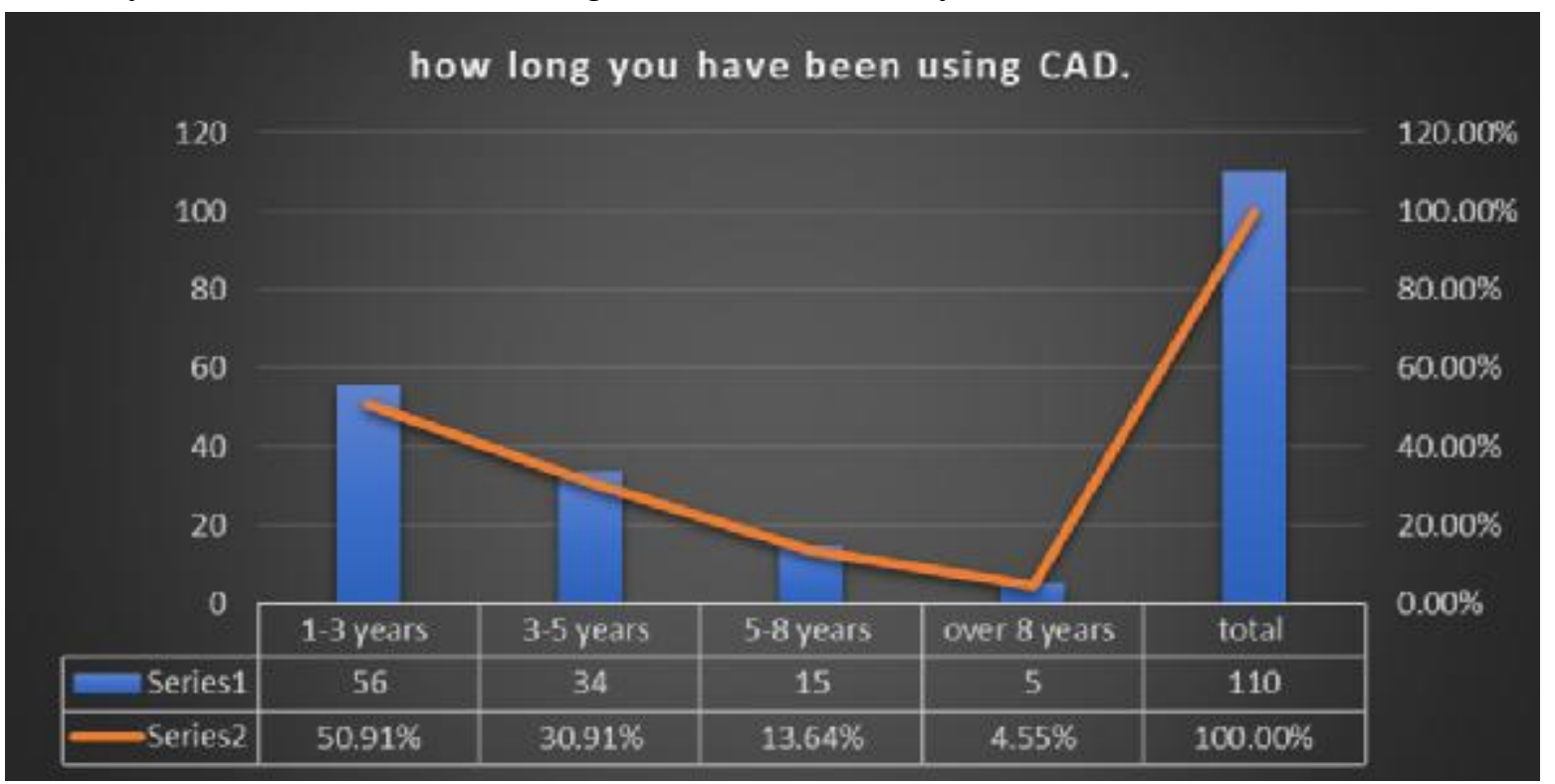

Figure 09 Questionnaire Results Q 01 (author).

year level and at the post graduated level. Most of the sample mentioned that they will start to learn Revit.

interestingly, from students point of view CAAD enhancing design creativity with more than 68 percent, while 13.8 percent disagree with this concept, while 20 percent said it's not clear if the CAAD or computer drafting tools enhancing design creativity. (see illustration No.2)

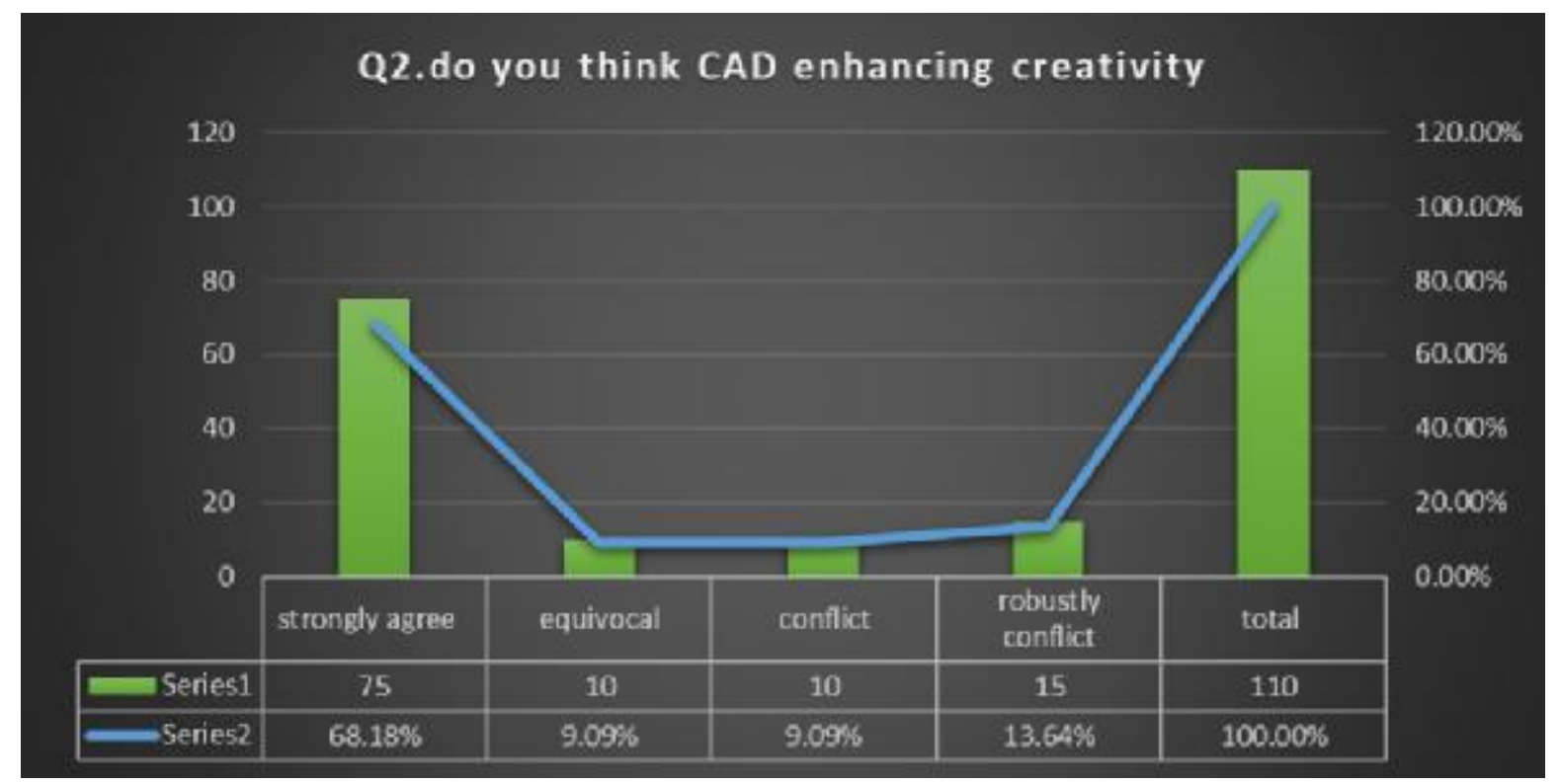

Figure 10 Questionnaire Results Q 02 (author). 
the third question was do you think manual drawings being better than the use of CAAD? The answers were robustly conflict with 86.36 percent, while only 6percent said the manual drawings is better than CAAD drawings, whilst the answers of 8.18 percent was equivocal. (see illustration No.3)

The questionnaire results demonstrated that, more than 85 percent using CAAD outputs to present primary ideas to their colleagues, lecturers and clients, while only 3.64percent using manual tools to present the primary ideas, this refers to the acquisition of computer tools to the interest of both students and practitioners of the profession. (see illustration No.4)

Through the questionnaire, when we asked about if CAAD tools enhancing the drawings quality, about 91percent was strongly agree, and only 0.91 percent was disagreed with this concept (see illustration No.5)

Question no.6 was about using of free hand to present primary ideas to their colleagues, lecturers and clients, 67.27 percent answered: scarcely, whereby 16.36 percent said: on occasion, only 5.45 percent said overwhelmingly. (see illustration No.6)

Despite the passion of students to use the CAAD... but they are often express their designs

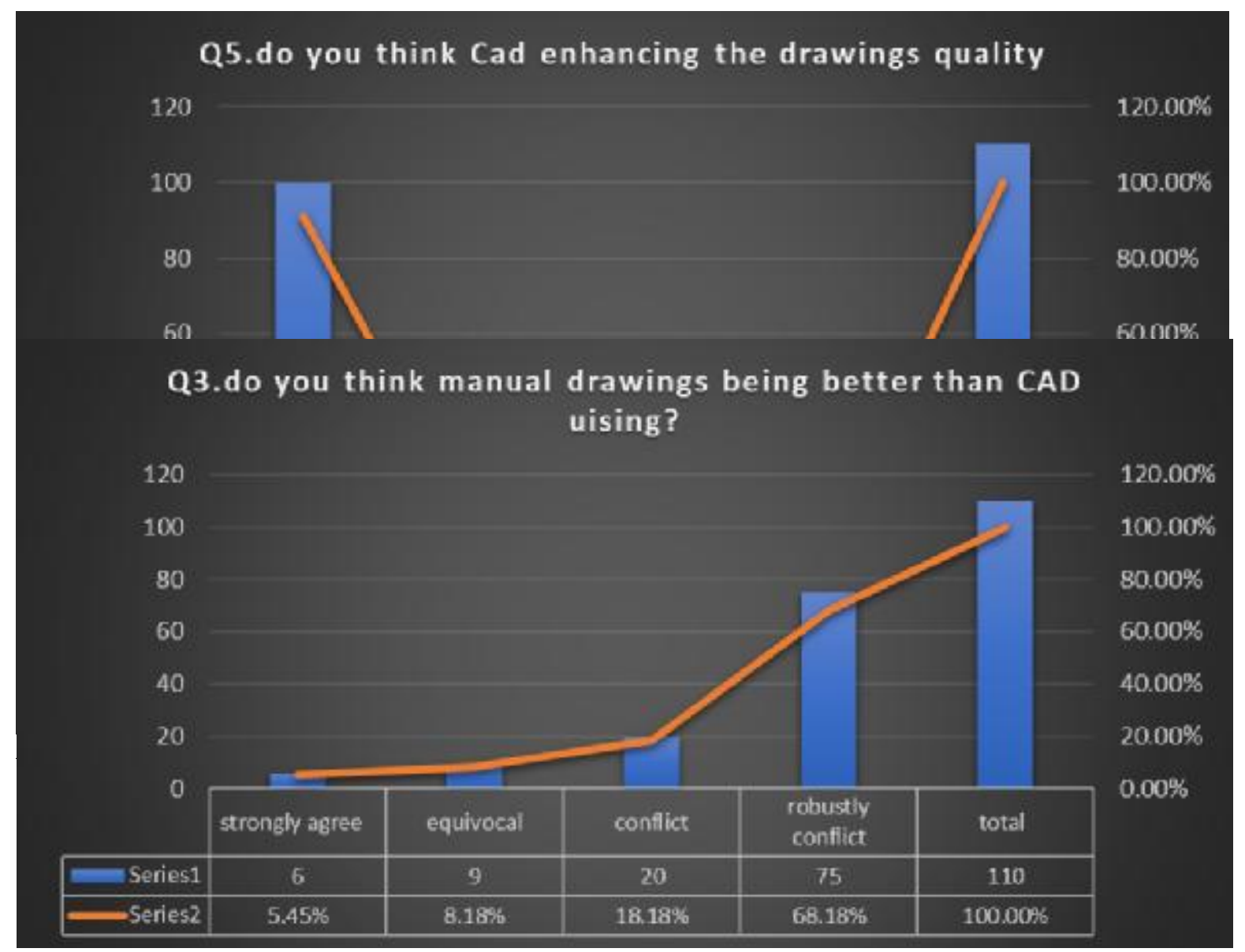

Figure 11 Questionnaire Results Q 03 (author).

through verbal communication, about 70.91 percent tend to use that method to reinforce their ideas, whilst 18.81 percent often rely on completed graphics only . (see illustration No.7) 


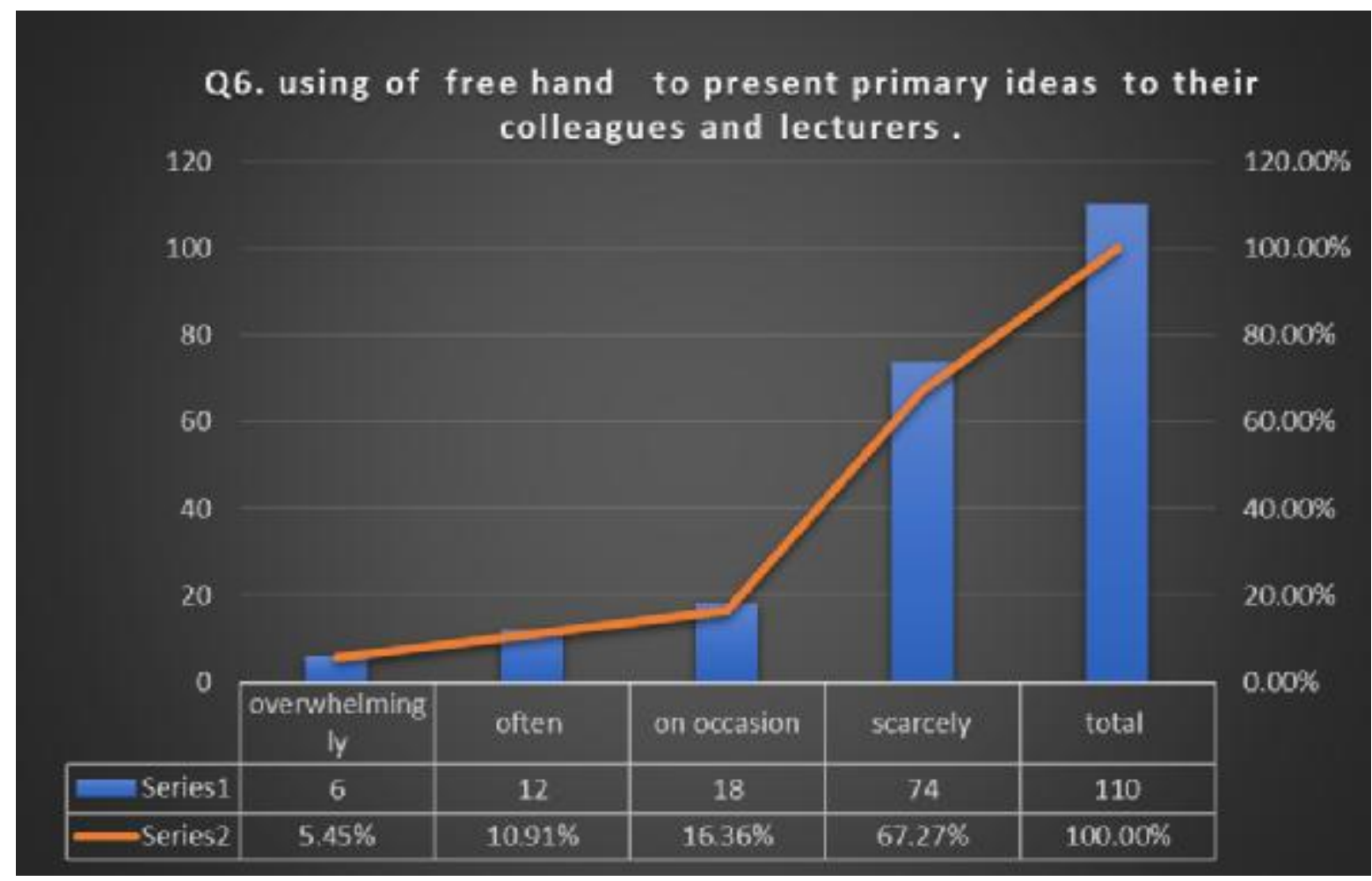

Figure 14 Questionnaire Results Q 06 (author).

\section{Q7. using of verbal communication to present primary} ideas to colleagues and lecturers.

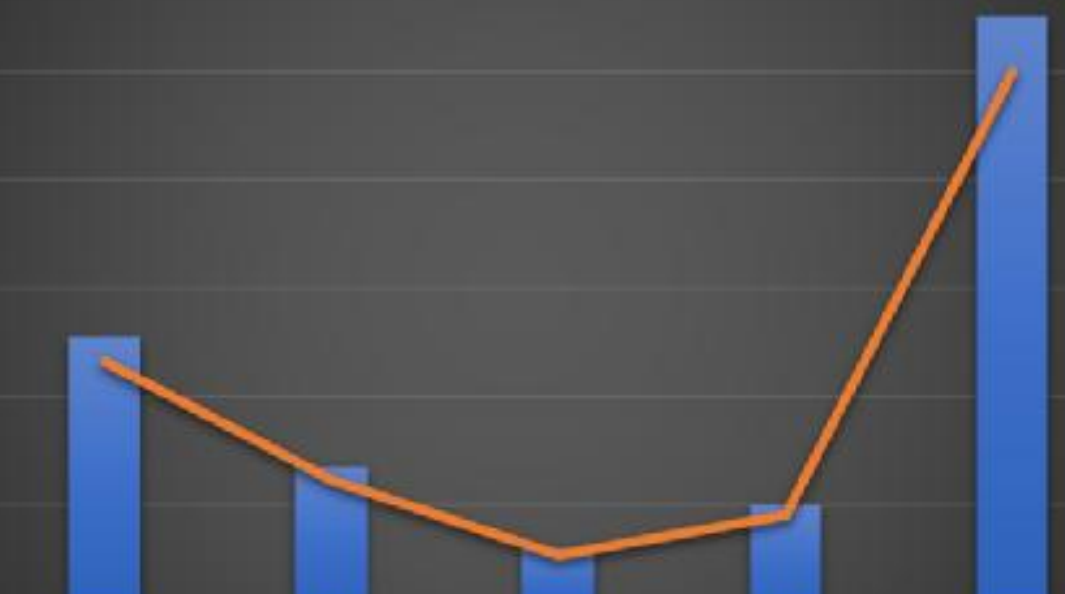

\begin{tabular}{|c|c|c|c|c|c|}
\hline 0 & overwhelmingly & often & on occasion & scarcely & total \\
\hline Series1 & 51 & 27 & 12 & 20 & 110 \\
\hline Series 2 & $46.36 \%$ & $24.55 \%$ & $10.91 \%$ & $18.18 \%$ & $100.00 \%$ \\
\hline
\end{tabular}

$80.00 \%$

Figure 14 Questionnaire Results Q 07 (author).

usage of the traditional board or manual tools to present primary ideas colleagues and lecturers drastically decreased, only 2.73 percent using this method, whilst 86.36 percent recognized it as an old fashion. (see illustration No.8).Regarding the issue of imitation of designs, the students confess that CAAD programs has contributed very much to support this process, while only 7.27 percent denied this idea(see illustration No.9) 


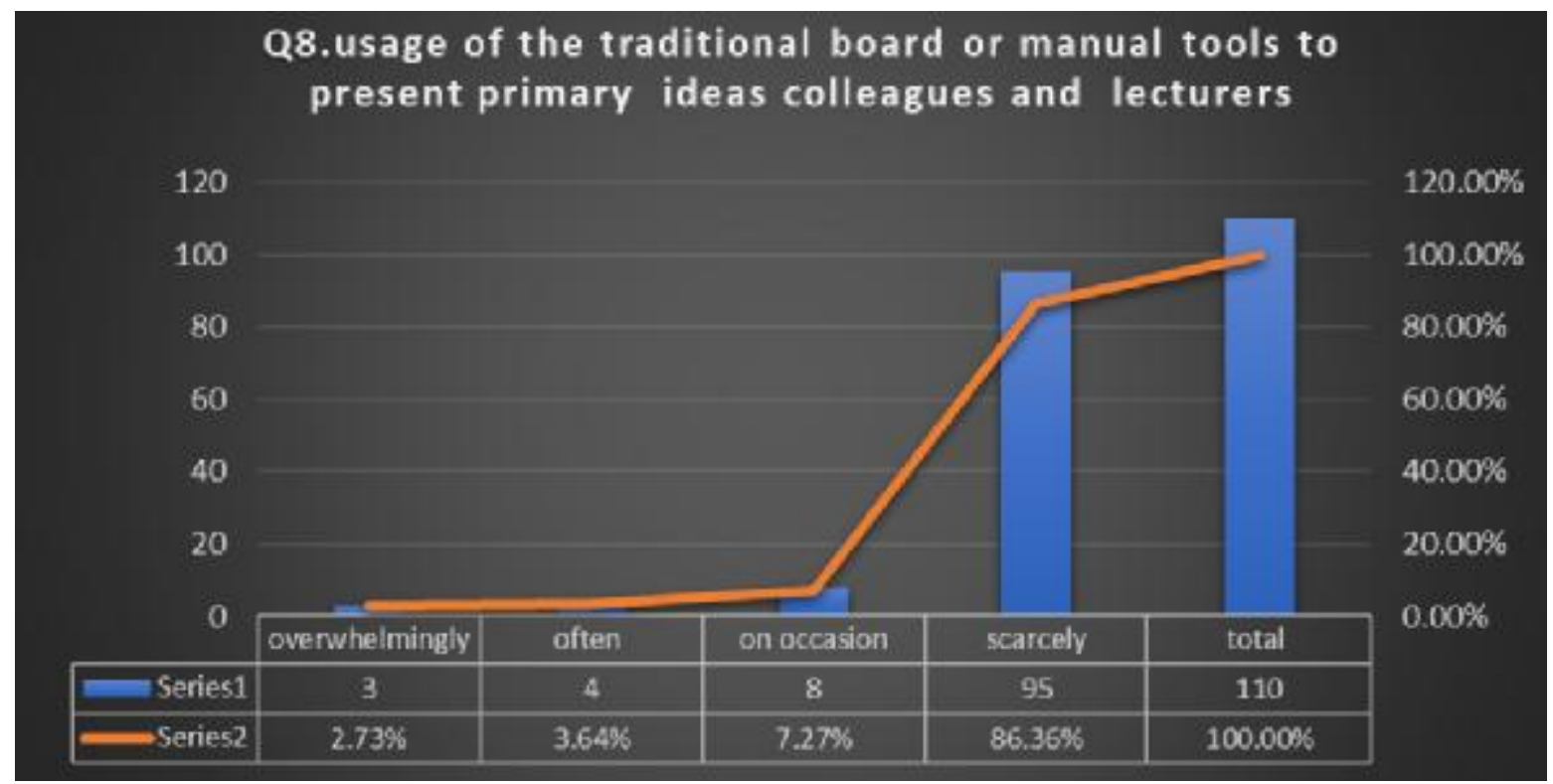

Figure 15 Questionnaire Results Q 08 (author).

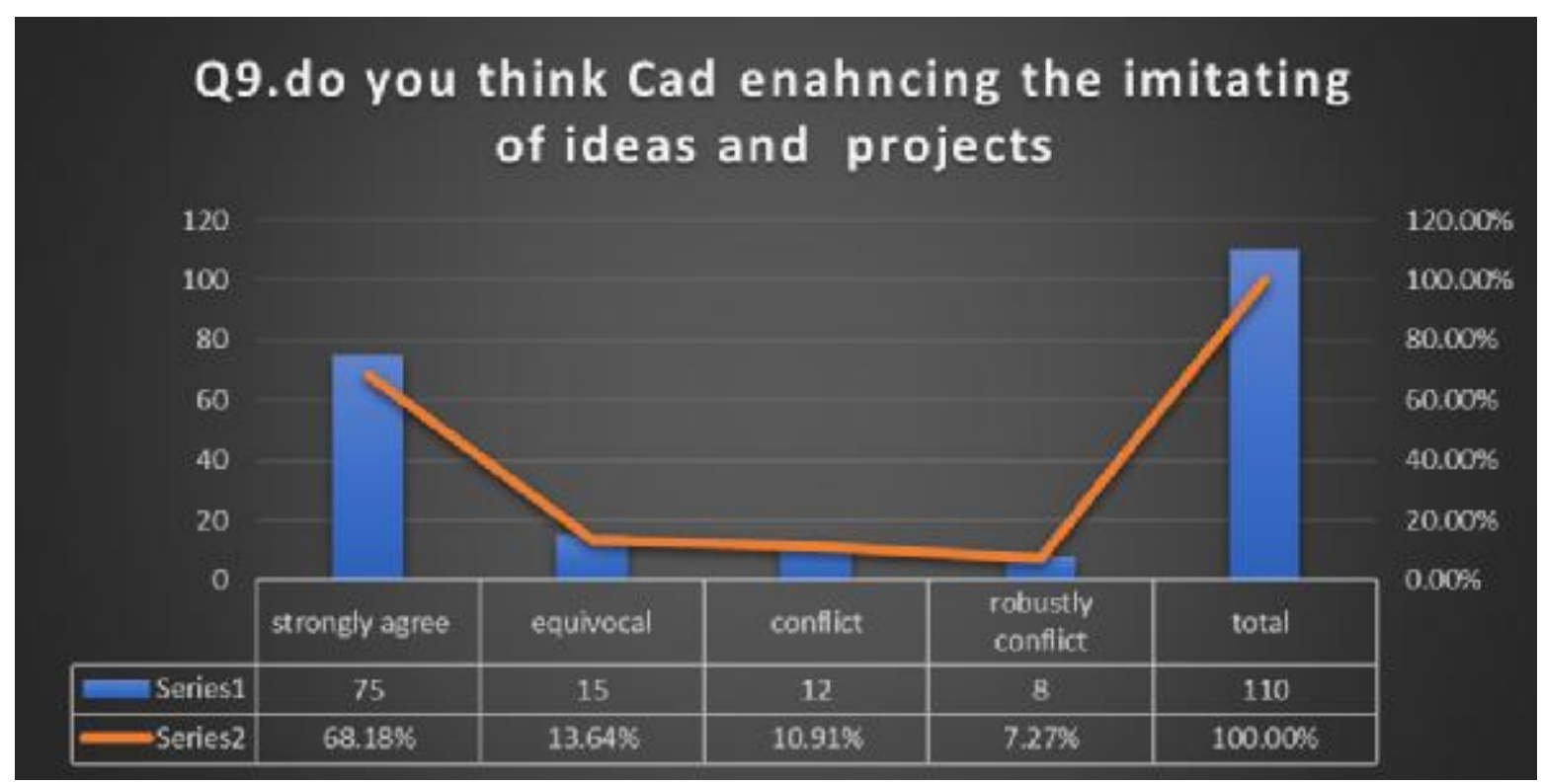

Figure 16 Questionnaire Results Q 09 (author).

\section{CONCLUSION}

It was very clear that students considering the CAAD tool is very effective in the production process and depends critically on it in designs and drafting. The use of CAAD also does not interrupt a student's and young architects thinking process or even make them sluggish. And whether we accept or reject the idea of students depend on the computer in the design, It seems that the practice of the profession in the future will depend on programs which supporting designs and drafting. As a lecturer, we must understand the acceleration of changes in this area, so that we can support the students well.

According to the questionnaire results, Most of students seeing that usage of hand tools in drafting $\ldots$ is kind of wasting time and effort ... although this skills are necessary and important to learn Architecture. Students expresses his ideas through multiple methods ,these methods could be freehand sketching, verbal communications, using CAAD tools and outputs and even the use of a traditional drawing board and T-square.

They also confiremed that there are efficiency improvement in design when using CAAD in terms of time and even the quality of final products. The use of CAAD should as much as possible be encouraged among students mainly not as a drafting tool only but also as 
technological tool which can support them to assess their designs because of its efficiency in design coupled with the fact that time and presentation are major considerations in today's world.Furthermore, digital tools should be applied as an essential part of the new design studio culture that integrates with other design subjects and courses in the architectural education curriculum. Various forms of interactive education systems such as video tutorials, electronic handbooks and so on should be adopted in the teaching of CAAD. The creation of a CAAD laboratory well stocked with high-end computers that should at least conform to the minimum specification for running CAAD software's, thus enhancing the teaching and learning experience of CAAD teaching.

In order to improvement student's skills in CAAD, we must to prepare preliminary investigation on the strength of students in the CAAD applications should be undertaken and less proficient students should be paired with students of high proficiency, Care should be taken so that students of equal proficiency in the CAAD application would not be paired together. CAAD will gradually become a natural partner in the design process when a broad population of architects and designers is familiar with all aspects of CAAD. CAAD opens the opportunity for the development of a new culture, in which the digital, the virtual and the physical coexist seamlessly and support each other to form a new whole. in conclusion, CAAD and digital tools shall be merged within the architectural design in early stages so that such tools would be used to provide creative design.

\section{REFERENCES}

1.Al-Matarneh, R., \& Fethi, I. J. M. O. J. o. E. T. (2017). Assessing the Impact of CAAD Design Tool on Architectural Design Education. 5(1), 1-20.

2. Al-Qawasmi, J. (2004). Reflections on e-design: the e-studio experience.

3. Alexiou, K., Zamenopoulos, T., Johnson, J., \& Gilbert, S. J. D. S. (2009). Exploring the neurological basis of design cognition using brain imaging: some preliminary results. 30(6), 623-647.

4. Amabile, T. M., Conti, R., Coon, H., Lazenby, J., \& Herron, M. J. A. o. m. j. (1996). Assessing the work environment for creativity. 39(5), 1154-1184.

5. Angelo, T. A., \& Cross, K. P. (2012). Classroom assessment techniques: Jossey Bass Wiley.

6. AP, O. O. J. I. J. o. E. R., \& Science, I. (2015). Effects of the Use of Computer Aided Design (CAD) On Architecture: A Quantitative Approach. 2(4), 67.

7. Asut, S. (2008). Rethinking the Creative Architectural Design in the Digital Culture. Paper presented at the Proceedings from First International Conference on Critical Digital, Harvard University Graduate School of Design, Cambridge (USA).

8. Barrett, T., Donnelly, R. J. E. i. i. t. p. o. u. 1., \& teaching. (2008). Encouraging students' creativity in higher education. 2, 115-130.

9. Birat, J.-P. J. I., \& Steelmaking. (2004). The relevance of Sir Henry Bessemer's ideas to the steel industry in the twenty-first century. 31(3), 183-189.

10. Botchway, E. A., Amos-Abanyie, S., \& Afram, S. O. (2015). The impact of Computer Aided Architectural Design tools on architectural design education. The case of KNUST.

11. Brown, P. J. I. T. S. J. o. S., Technology,, \& Society. (2009). CAD: Do computers aid the design process after all?, 2(1), 52-66.

12. Ceccato, C., Hesselgren, L., Pauly, M., Pottmann, H., \& Wallner, J. (2016). Advances in Architectural Geometry 2010: Birkhäuser.

13. El Shafie, H. (2000). Computer applications in architecture: form generation tools. Thesis,

14. Femenías, P. (2004). Demonstration projects for sustainable building: towards a strategy for sustainable development in the building sector based on Swedish and Dutch experience: Chalmers University of Technology.

15. Gero, J. J. A. i. B. T., Elsevier, Amsterdam. (2002). Advances in IT for building design. 47-54.

16. Goetzeler, H. J. T. P. T. (1994). Werner von Siemens-The scientist as innovator and entrepreneur. 32(6), 332-337. 
17. Guney, D. J. P.-S., \& Sciences, B. (2015). The importance of computer-aided courses in architectural education. 176, 757-765.

18. Hatem, E. S. (2005). Computer application in architecture: Form generation tools.

19. Jefferis, A., \& Madsen, D. A. (2005). Architectural drafting and design: Cengage Learning.

20. Kane, P. (2005). The play ethic: A manifesto for a different way of living: Pan Macmillan.

21. Kozbelt, A., Beghetto, R. A., \& Runco, M. A. J. T. C. h. o. c. (2010). Theories of creativity. 2, 20-47.

22. Kyratsis, P., Bilalis, N., \& Antoniadis, A. J. C.-A. D. (2011). CAD-based simulations and design of experiments for determining thrust force in drilling operations. 43(12), 1879-1890.

23. Lawson, B. R. J. E. (1979). Cognitive strategies in architectural design. 22(1), 59-68.

24. MÂRŞANU, N. R., Rusu, S. M. J. T., \& Management, E. R. i. U. (2010). Computer aided design in urban architecture 3D modeling. 5(5 (14), 147-164.

25. Moore, J. M. J. I. J. o. P. R. (1974). Computer aided facilities design: an international survey. 12(1), 21-44.

26. Oxman, R. J. D. s. (2006). Theory and design in the first digital age. 27(3), 229-265.

27. Robinson, K. (2011). Out of our minds: Wiley Online Library.

28. Saracoglu, B. O., \& Gozlu, S. (2006). Identification of Technology Performance Criteria for CAD/CAM/CAE/CIM/CAL in Shipbuilding Industry. Paper presented at the 2006 Technology Management for the Global Future-PICMET 2006 Conference.

29. Sidawi, B. (2013). Rethinking architectural education: A focus on creativity. Paper presented at the AAE conference, Nottingham Trent University, Nottingham, United K-ingdom.

30. Szalapaj, P. (2013). CAD principles for architectural design: Routledge.

31. Walther, J., Robertson, B., Radcliffe, D. J. D. o. C. S., \& Software Engineering, T. U. o. M. (2007). Avoiding the potential negative influence of CAD tools on the formation of students' creativity. 20107.

32. Williams, A., Ostwald, M., \& Askland, H. H. (2010). Assessing creativity in the context of architectural design education. Paper presented at the Proceedings from Design \& Complexity International Conference.

33. Whitehead, B., and Eldars, M. Z. An approach to the optimum layout of singlestorey buildings. The Architects" Journal (17 June), 1964, 1373-1380. 